\title{
Lymphoscintigraphy of Chylous Anomalies: Chylothorax, Chyloperitoneum, Chyluria, and Lymphangiomatosis-15-Year Experience in a Pediatric Setting and Review of the Literature
}

\author{
Sophie Turpin and Raymond Lambert \\ Nuclear Medicine, Medical Imaging, CHU Sainte-Justine, Montréal, Quebec, Canada
}

\begin{abstract}
In the pediatric setting, lymphoscintigraphy is used mostly for the evaluation of lymphedema. Only a few cases of chylous anomalies and lymphatic malformations imaged with lymphoscintigraphy have been reported in the literature. The aim of this study was to review the use of lymphoscintigraphy in those pathologies. Methods: All lymphoscintigraphy studies performed for chylous anomalies between 2001 and 2017 in our hospital were retrospectively reviewed. The results were correlated to clinical and radiologic findings. Lymphoscintigraphy consisted of sequential imaging after injection of 3.7-9.25 MBq (100-250 $\mu \mathrm{Ci}$ ) of 99mTc-filtered sulfur colloid at the level of the feet or hands. Results: Twenty-five studies were performed on 21 patients. Fourteen studies were obtained for the evaluation of chylothorax. Eleven were performed for chyloperitoneum, chyluria, chylopericardium, exudative enteropathy, or lymphangiomatosis. Ten studies were positive for lymphatic leakage, and 1 had uncertain results. After correlation with radiologic findings and follow-up, there were 7 true-negative and 5 false-negative results (previous ${ }^{67} \mathrm{Ga}$-interfering activity in 1 , injection in only the hands in 3 , and a low-fat diet in 1). One study became positive after injection in the feet, and another became positive after a switch to a high-fat diet. Conclusion: Lymphoscintigraphy is a useful tool for imaging lymphatic anomalies in children. Suggestions to optimize results include placing the patient on a high-fat diet, withholding octreotide, injecting the 4 extremities, and imaging with SPECT/CT.
\end{abstract}

Key Words: lymphoscintigraphy; children; chylothorax; chyloperitoneum; lymphangiomatosis

J Nucl Med Technol 2018; 46:123-128

DOI: 10.2967/jnmt.117.203281

$\mathbf{L}$

ymphatic anomalies are globally rare in newborns and children but in some cases can lead to significant morbidity and mortality. Of interest are the chylous effusions that can occur in the thorax, abdomen, pericardium, or urinary tract. In a tertiary pediatric setting, chylothorax and chyloperito-

Received Oct. 4, 2017; revision accepted Nov. 30, 2017.

For correspondence contact: Sophie Turpin, Nuclear Medicine, Medical Imaging, CHU Sainte-Justine, 3175, Chemin de la Côte-Sainte-Catherine, Montréal H3T 1C5, Quebec, Canada.

E-mail: turpinsop@hotmail.com

Published online Feb. 2, 2018.

COPYRIGHT (C) 2018 by the Society of Nuclear Medicine and Molecular Imaging. neum are encountered with increasing frequency as patients have surgeries from a very young age for congenital heart disease. Patients with vascular or lymphatic congenital malformations are also referred to a tertiary pediatric center and may need imaging. The purpose of our study was to review our experience with such patients in the last $15 \mathrm{y}$.

\section{MATERIALS AND METHODS}

Between 2001 and 2017, 171 lymphoscintigraphic studies were performed in our pediatric hospital. After exclusion of patients evaluated for lymphedema, Klippel-Trenaunay syndrome, and sentinel node mapping, 25 studies on 21 patients remained. The clinical presentation for which these studies were done included lymphatic anomalies, chylothorax, chylopericardium, chyloperitoneum, chyluria, lymphangiomatosis, and lymphangiectasia.

This retrospective study was approved by the Medical Affairs Direction, which allowed use of data on file without patient or parental consent.

After the procedure had been explained to the patient and parents, ${ }^{99 \mathrm{~m}} \mathrm{Tc}$-filtered sulfur colloid was injected using a tuberculin syringe, under sterile conditions, at the level of the feet and hands. The dose ranged from $3.7 \mathrm{MBq}(100 \mu \mathrm{Ci})$ in infants and toddlers (injected using a 27 -gauge, $1.3-\mathrm{cm}$ needle) to $9.25 \mathrm{MBq}$ $(250 \mu \mathrm{Ci})$ in older children (injected using a 25 -gauge, $1.3-\mathrm{cm}$ needle). The injected volume was between 0.1 and $0.25 \mathrm{~mL}$. In most cases, intradermal injections were performed at the level of the first interdigital space, but some very tiny patients had subcutaneous injections. We were not able to inject some patients in all 4 extremities because of their clinical condition or the presence of a saturometer device or intravenous access. Lymphoscintigraphy consisting of anterior and posterior sequential dynamic images of the regions of interest was performed for $60-120 \mathrm{~min}$, followed by delayed imaging if needed, including a 24-h study (Fig. 1). If present, the drain casing was also imaged.

The lymphoscintigraphy results were correlated to clinical and paraclinical data and to follow-up data. Negative lymphoscintigraphy results were considered false-negative if the abnormalities were proven to be present at the time of lymphoscintigraphy by other modalities or clinical findings.

\section{RESULTS}

Of our 21 patients, 6 were 4 mo old or younger, 7 were between $10 \mathrm{mo}$ and $5 \mathrm{y}$ old, and the remainder were $8 \mathrm{y}$ old or older (Table 1). No patients were receiving octreotide at the time of the examination. However, drains were present 


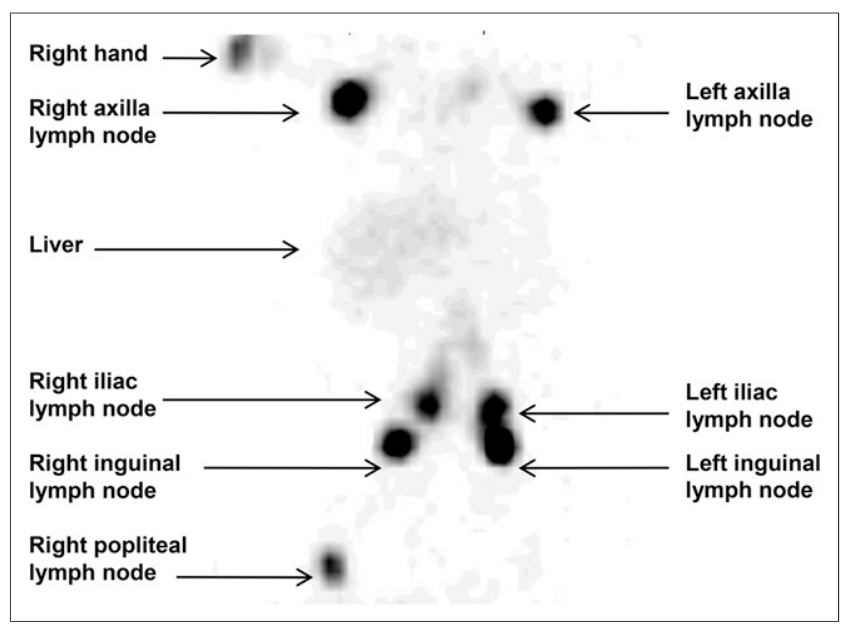

FIGURE 1. Normal lymphoscintigraphy findings after injection in upper and lower extremities.

in some patients, and some patients were being parentally fed.

Patients 1-7 developed chylothorax after cardiac surgery for congenital heart disease (Fontan and Damus-Kaye-Stansel procedures in 6 patients and cardiac transplantation in 1 patient). Lymphoscintigraphy showed pleural accumulation in only patients 2 and 7, was equivocal for left-sided chylothorax in patient 6 , had true-negative findings in patients 1 and 3, and had false-negative findings in patients 4 and 5 (showing no abnormal uptake, but those 2 patients were injected only in the hands because of clinical instability).

Patients 8-11 presented with congenital chylothorax. The lymphoscintigraphy findings were negative in patients $8-10$. However, patient 8 was injected only in the hands. The diagnosis in patient 10 was changed from congenital chylothorax to pseudochylothorax after pneumonia occurred during follow-up. In patient 11, who was a 1-moold with gastroschisis, the lymphoscintigraphy findings were normal after injection in the hands but positive after injection in the feet a few days later (Fig. 2).

Patients 12-14 were known to have lymphangiomatosis and chylothorax. Patient 12 was a 15-y-old with Gorham disease. He was evaluated for recurrent chylothorax, and the study was positive after injection in both hands (Fig. $3)$. In patient 13 , lymphoscintigraphy was nondiagnostic because of ${ }^{67} \mathrm{Ga}$ interference from a previous study. Patient 14 was imaged 3 times between the ages of 12 and $15 \mathrm{y}$. She had a history of congenital chylothorax and hydrops fetalis. At age 12, she had been evaluated for chylothorax, with true-negative imaging findings. At age $15 \mathrm{y}$, she was imaged again for lymphatic malformations and chylopericardium necessitating drainage. After normal results were found on lymphoscintigraphy, the patient was switched from a normal diet to a high-fat diet. Control lymphoscintigraphy demonstrated soft-tissue lymphangiomatosis, but although there was no frank accumulation in the pericardium, some activity was seen in the drainage bag (Fig. 4).
Patient 15 had a history of recurrent chylothorax and chyloperitoneum since birth. The underlying pathology was also lymphangiomatosis. She was imaged twice with lymphatic studies, which had true-negative findings.

Patients 16-20 were evaluated for chyloperitoneum or for the possibility of intestinal lymphangiectasia. Patient 16 was a 10-mo-old with complex cardiopathy after having undergone Damus-Kaye-Stansel surgery, right ventriclepulmonary artery conduit cardiac surgery, and gastrostomy. He developed chyloperitoneum, which was demonstrated on lymphoscintigraphy after injection in the 4 extremities (Fig. 5). Patient 17, who was also 10 mo old, had recurrent chyloperitoneum after sclerotherapy. After injection in both feet, extravasation of the tracer was seen in the region of the cisterna chyli. Abnormal dysplastic lymphatics with

TABLE 1

Patient Characteristics

\begin{tabular}{|c|c|c|c|c|}
\hline $\begin{array}{l}\text { Patient } \\
\text { no. }\end{array}$ & Age & Sex & Presentation & Finding \\
\hline 1 & $11 \mathrm{mo}$ & $\mathrm{F}$ & $\begin{array}{l}\text { Chylothorax after } \\
\text { cardiac surgery }\end{array}$ & $\mathrm{TN}$ \\
\hline 2 & $4 y$ & M & $\begin{array}{l}\text { Chylothorax after } \\
\text { cardiac surgery }\end{array}$ & TP \\
\hline 3 & $4 \mathrm{mo}$ & $M$ & $\begin{array}{l}\text { Chylothorax after } \\
\text { cardiac surgery }\end{array}$ & $\mathrm{TN}$ \\
\hline 4 & $5 y$ & $\mathrm{~F}$ & $\begin{array}{l}\text { Chylothorax after } \\
\text { cardiac surgery }\end{array}$ & $\mathrm{FN}$ \\
\hline 5 & $1 \mathrm{mo}$ & $\mathrm{F}$ & $\begin{array}{l}\text { Chylothorax after } \\
\text { cardiac surgery }\end{array}$ & $\mathrm{FN}$ \\
\hline 6 & $18 \mathrm{y}$ & M & $\begin{array}{l}\text { Chylothorax after } \\
\text { cardiac surgery }\end{array}$ & $\begin{array}{l}\text { TP } \\
\text { or FN }\end{array}$ \\
\hline 7 & $2 \mathrm{mo}$ & $M$ & $\begin{array}{l}\text { Chylothorax after } \\
\text { cardiac surgery }\end{array}$ & TP \\
\hline 8 & $1 \mathrm{mo}$ & M & $\begin{array}{l}\text { Idiopathic congenital } \\
\text { chylothorax }\end{array}$ & $\mathrm{FN}$ \\
\hline 9 & $1 \mathrm{mo}$ & $\mathrm{F}$ & $\begin{array}{l}\text { Idiopathic congenital } \\
\text { chylothorax }\end{array}$ & $\mathrm{TN}$ \\
\hline 10 & $4 y$ & $\mathrm{~F}$ & Pseudo chylothorax & TN \\
\hline 11 & $1 \mathrm{mo}$ & $M$ & $\begin{array}{l}\text { Congenital chylothorax/ } \\
\text { gastroschisis }\end{array}$ & TP \\
\hline 12 & $15 y$ & M & $\begin{array}{l}\text { Chylothorax/ } \\
\text { lymphangiomatosis }\end{array}$ & TP \\
\hline 13 & $13 y$ & $\mathrm{~F}$ & $\begin{array}{l}\text { Chylothorax/ } \\
\text { lymphangiomatosis }\end{array}$ & $\mathrm{FN}$ \\
\hline 14 & $15 y$ & $\mathrm{~F}$ & $\begin{array}{l}\text { Chylothorax/ } \\
\text { lymphangiomatosis }\end{array}$ & $\begin{array}{l}\text { See } \\
\text { text }\end{array}$ \\
\hline 15 & $3 y$ & $\mathrm{~F}$ & $\begin{array}{l}\text { Chyloperitoneum/ } \\
\text { lymphangiectasia }\end{array}$ & $\mathrm{TP}$ \\
\hline 16 & $10 \mathrm{mo}$ & M & $\begin{array}{l}\text { Chyloperitoneum after } \\
\text { cardiac surgery }\end{array}$ & TP \\
\hline 17 & $10 \mathrm{mo}$ & $M$ & $\begin{array}{l}\text { Chyloperitoneum/ } \\
\text { lymphangiomatosis }\end{array}$ & TP \\
\hline 18 & $9 y$ & $\mathrm{~F}$ & $\begin{array}{l}\text { Abdominal } \\
\text { lymphangiomatosis }\end{array}$ & TP \\
\hline 19 & $16 y$ & $\mathrm{~F}$ & Exudative enteropathy & TN \\
\hline 20 & $16 y$ & $M$ & Exudative enteropathy & TN \\
\hline 21 & $8 y$ & M & Chyluria & NA \\
\hline
\end{tabular}

$\mathrm{TN}=$ true-negative; TP = true-positive; $\mathrm{FN}=$ false-negative; $\mathrm{NA}=$ not applicable. 


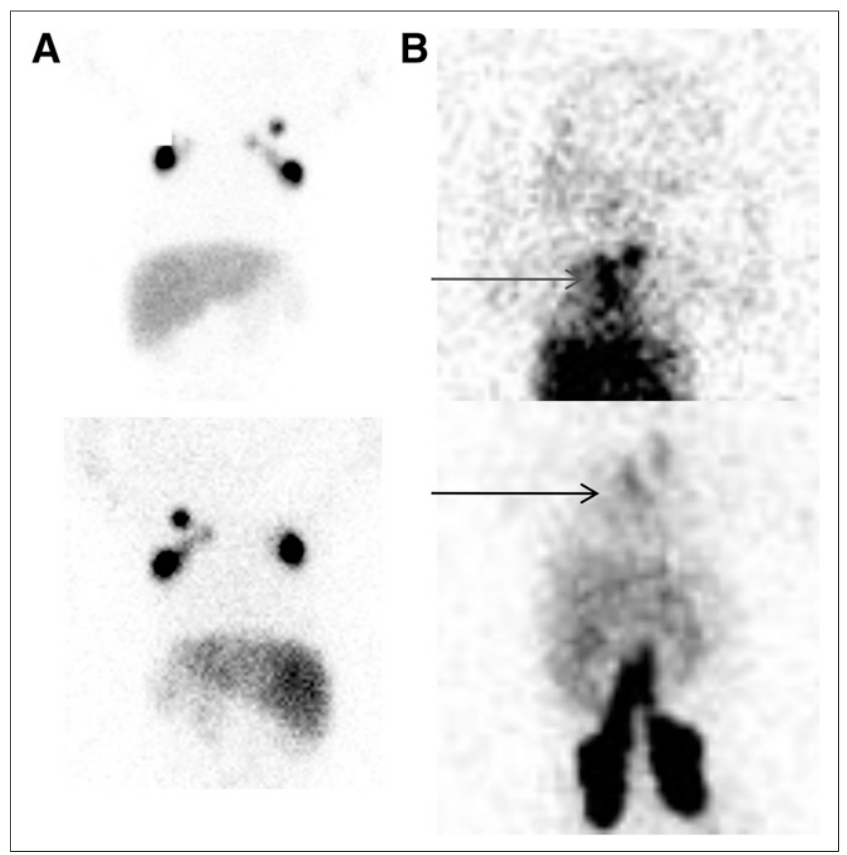

FIGURE 2. Congenital chylothorax. (A) No abnormal accumulation after injection in both hands: anterior view (top) and posterior view (bottom) of thorax with activity in axillary lymph nodes. (B) Thoracic accumulation of tracer (arrows), including in thoracic canal region, after injection in both feet: anterior view (top) and posterior view (bottom) with visualization of ilioinguinal lymph nodes.

an intraabdominal leak were confirmed by lymphography (Fig. 6).

Finally, patient 21 was evaluated for chyluria, without a history of previous cancer, surgery, or filariasis. No leakage was demonstrated on lymphoscintigraphy. Investigation over a period of $3 \mathrm{y}$ did not establish the origin of the chyluria.

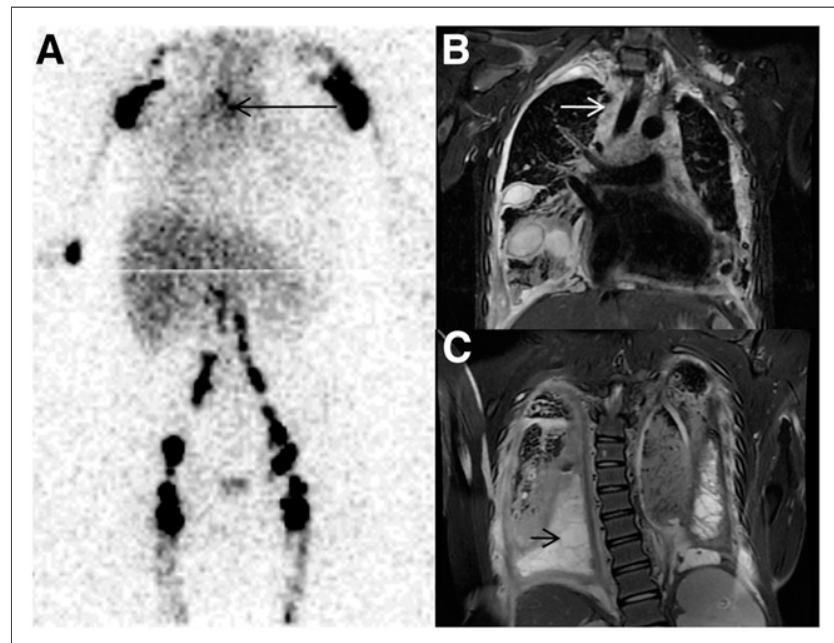

FIGURE 3. Gorham disease. (A) Abnormal accumulation of tracer in mediastinum (arrow) after injection in both upper and lower extremities. (B and $\mathrm{C}$ ) MR images showing diffuse infiltration of mediastinum (arrow) secondary to lymphangiomatosis $(B)$ and presence of loculated chylothorax (arrow) (C).

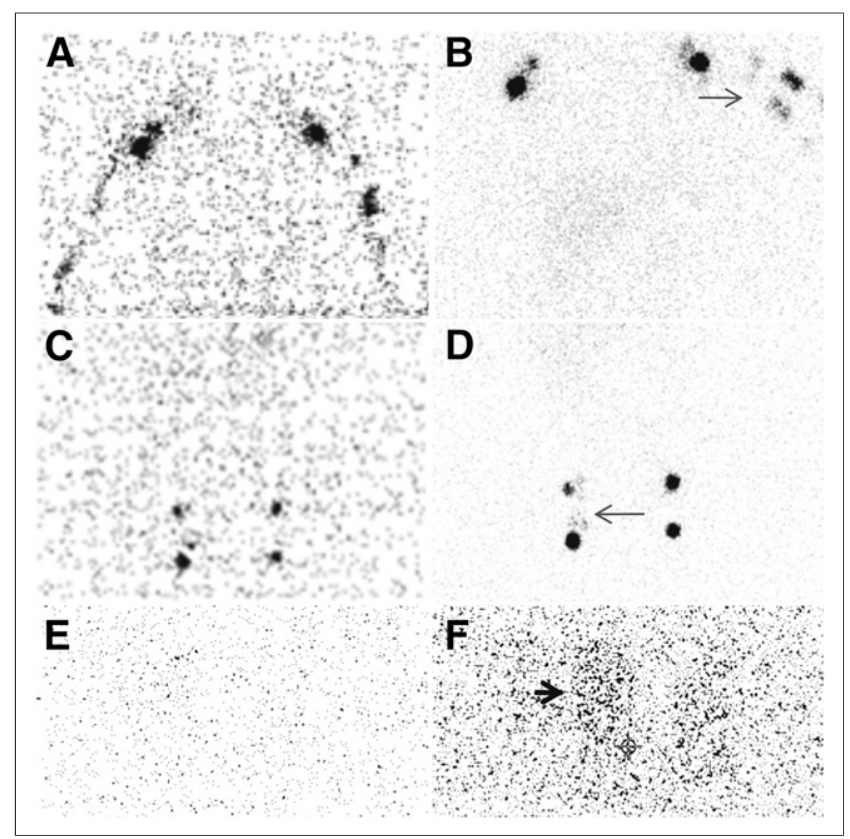

FIGURE 4. Lymphangiomatosis in patient with chylopericardium necessitating drainage. (A and $C$ ) Normal findings with standard diet: injection in upper (A) and lower (C) extremities. (E) No activity in collecting bag. (B and D) Left shoulder and right inguinal region showing lymphangiectasia (arrows) on lymphoscintigraphy performed after switching patient to high-fat diet: injection in upper (B) and lower (D) extremities. (F) Activity (arrow) in collecting bag.

\section{DISCUSSION}

The thoracic duct is the main collecting system of the body's lymph and chyle. Lymph originating from the abdomen and lower extremities drains through lumbar lymph nodes to the cisterna chyli, located in front of L2. The thoracic duct then travels in the retrocrural space on the

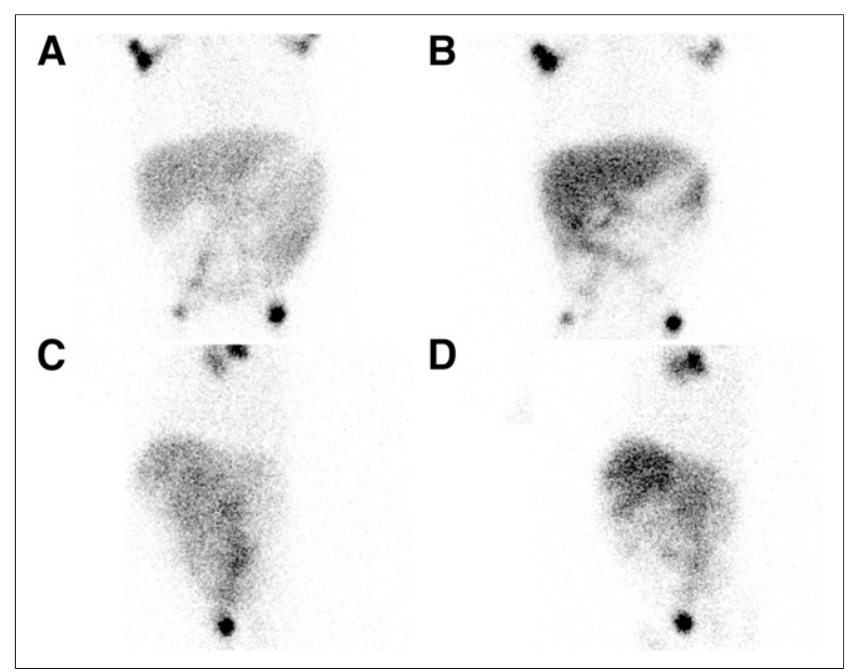

FIGURE 5. Chyloperitoneum. After injection in the 4 extremities, abnormal accumulation of tracer in abdomen at $1 \mathrm{~h}$ on anterior $(A)$ and left lateral $(C)$ views and at $5 \mathrm{~h}$ on anterior (B) and left lateral (D) views. 


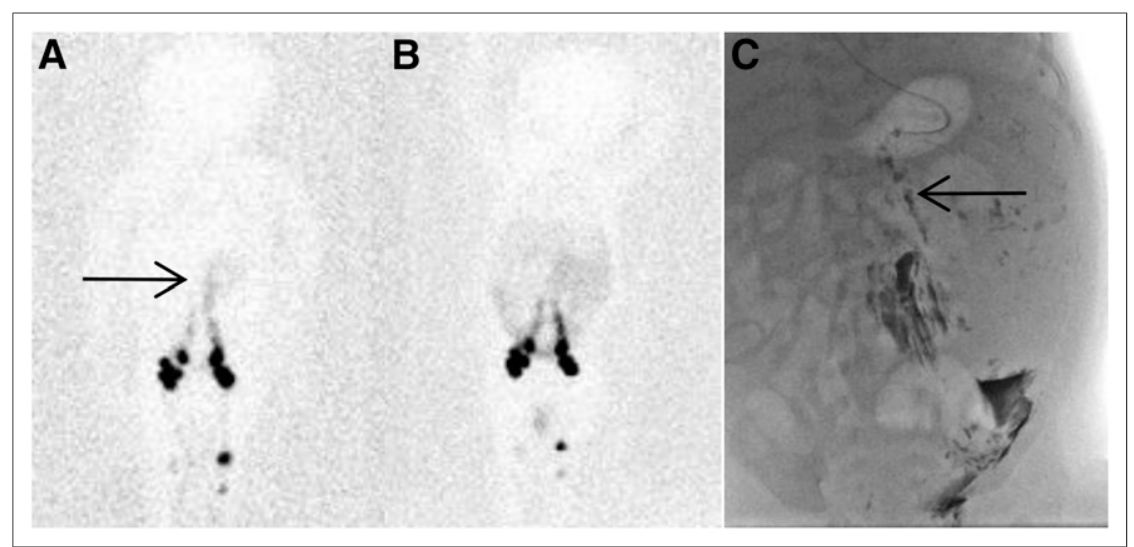

FIGURE 6. (A) After injection in the lower extremities, lymphoscintigraphy image at $1 \mathrm{~h}$ demonstrating leak (arrow). (B) Diffuse intraabdominal accumulation at $5 \mathrm{~h}$ after injection. (C) Conventional lymphography showing dysplastic lymphatics (arrow) and intraabdominal leak.

right side of the aorta and crosses the midline at the level of T5, through the aortic arch, to drain in the left subclavian vein (1-4). The right side of the upper body and the head drains into the right lymphatic duct, which empties in the right subclavian vein (Fig. 7). Anatomic variations are frequent (3).

Chyle is responsible for the transport of ingested fats, with most chyle originating from the liver and gastrointestinal tract. Chyle flow increases significantly after a meal, depending on the diet, potentially influencing lymphoscintigraphy $(2,4,5)$. Transport along the thoracic duct is mediated by a pressure gradient between the thorax and the abdomen, tissue hydrostatic pressure, and the Bernoulli effect at the entrance of the subclavian vein $(3,5)$. More than $2 \mathrm{~L}$ of lymph empty in the circulation each day. Chyle is responsible for the transport of lipids from the gastrointestinal tract into the circulation but also for the transfer of fluids, proteins, and lymphocytes between the interstitial and intravascular compartments (6).

Chylothorax is probably the most frequent type of abnormal chylous accumulation. It can be caused by noniatrogenic

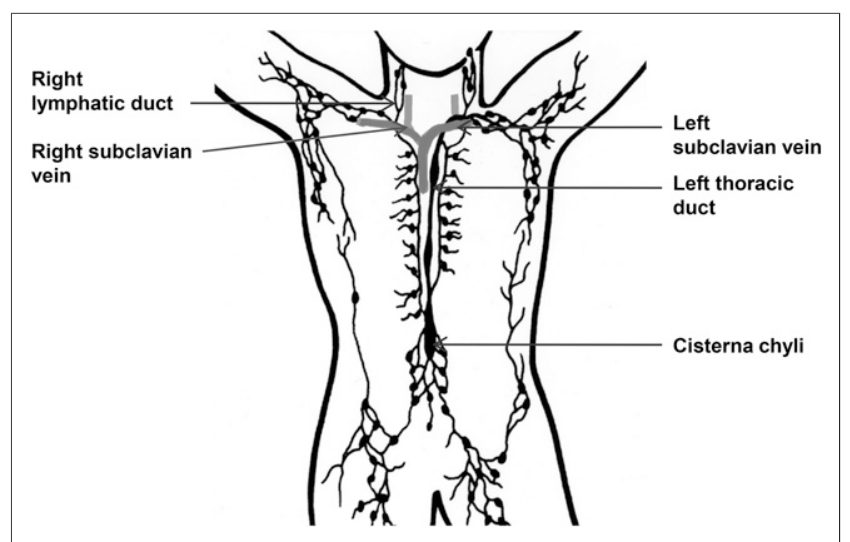

FIGURE 7. Anatomy of lymphatic system. (Adapted from Wikimedia Commons.) trauma, surgery, or invasive diseases, or it can be congenital $(3,5,7)$. Congenital chylothorax is found in the neonatal period and can be associated with malformations such as Noonan disease or Down syndrome, hydrops fetalis, congenital lymphangiectasia, or lymphangiomatosis. It is suggested that the presence of a congenital weakness associated with the trauma of birth may cause congenital chylothorax in some patients (3).

Because of the location of the thoracic duct, posttraumatic chylothorax is more frequent on the right side in adults (8). However, in children, it can be found on the left side, after cardiac surgery involving the aortic region (e.g., esophageal atresia repair, aortic coarctation repair, or Blalock-Taussig shunt) (9). It is most frequent after heart transplantation and Fontan procedures, and chyloperitoneum may also occur (10).

Postsurgical chylothorax is rare in adults, occurring as a complication of $0.25 \%-0.5 \%$ of intrathoracic procedures, but is more frequent in children, at $2.5 \%-4.7 \%(5,10)$.

Finally, mostly in adults, chylothorax may complicate lymphoma, esophageal cancer, tuberculosis, filariasis, lymphangioleiomyomatosis, and Gorham disease, as in some of our patients.

For the evaluation of chylous effusion, the lymphoscintigraphy procedure is similar to the one used for lymphedema. However, the 4 extremities must be injected, which can be difficult in very young patients or in intensive care patients. Because of the lack of availability of ${ }^{99 \mathrm{~m}} \mathrm{Tc}-$ antimony, ${ }^{99 \mathrm{~m}} \mathrm{Tc}-d e x t r a n$, and ${ }^{99 \mathrm{~m}} \mathrm{Tc}-$-nanoalbumin, the radiotracer of choice is ${ }^{99 \mathrm{~m}} \mathrm{Tc}$-filtered sulfur colloid. Intradermal injections in the interdigital spaces are usually used but can be replaced by subcutaneous ones. Injected activities range from 3.7 to $9.25 \mathrm{MBq}$ in small volumes of around $0.1 \mathrm{~mL}$. More invasive subfascial injections, allowing the evaluation of the deep lymphatic system, are not used in our institution (1). Treatment options include a parenteral low-fat diet and octreotide to reduce intestinal chyle production, drainage, and thoracic duct ligation $(4,10)$. Withholding medication or reintroducing a high-fat diet may be needed to decrease the possibility of false-negative results, as in patient 14 .

Only 2 cases of lymphoscintigraphy performed on very young patients could be found in the literature: a 2-mo-old boy with congenital chylothorax (11) and a neonate with chylothorax after cardiac surgery (12). We had 9 patients less than $1 \mathrm{y}$ old in our population, and injection in some of those patients was more challenging.

Chylothorax is differentiated from pseudo chylothorax by its high triglyceride content (4), which is a complication of long-standing exudate rich in cholesterol because of fatty degeneration of cells $(7,8)$. Pseudochylothorax 
after lung infection was eventually demonstrated in patient 10 .

Among rare causes of chylothorax, we can include lymphangioleiomyomatosis and hemangiomatosis (4). Lymphangioleiomyomatosis is characterized by smooth muscle proliferation in the lungs, lymph nodes, and thoracic duct. It is found almost exclusively in women and leads to respiratory failure. Most patients will present with chylothorax $(4,7)$. Hemangiomatosis or Gorham disease is characterized by vascular and lymphatic proliferation in the bones or in the soft tissues. Intrathoracic lesions, such as in one of our patients, are found in less than $1 \%$ of cases $(4,13)$. Complications include chylothorax, disseminated intravascular coagulation, infection, and malnutrition.

Some of our patients had chyloperitoneum, usually associated with other pathologies. Chyloperitoneum can be exudative with chyle retrodiffusion after central obstruction by malignancy, infectious, or fistulous, with the presence of enlarged retroperitoneal lymphatics (14). Chyloperitoneum may also occur after trauma or surgery, as in patient 16 , or be congenital in origin (associated with intestinal lymphangiectasia, as in patient 15 , or with lymphangiomatosis, as in patient 17) (15).

Primary intestinal lymphangiectasia is characterized by intestinal megalymphatics and protein-losing enteropathy, and lymphoscintigraphy can be demonstrated by abnormal accumulation of the tracer not only in the digestive tract but in various effusions, as shown in 41 patients by Wen et al. (16).

Chyluria (14) is secondary to a fistula between the paraaortic lymph nodes and the kidney, with backflow toward the renal lymph nodes and extravasation in the collecting system. It is associated with filariasis, cancer, abdominal surgery (including live-donor nephrectomy, renal transplantation, and oncologic procedures (17-19)), or lymphangiitis (20). Forty-one patients with chyluria were imaged using ${ }^{99 m}$ Tc-dextran, and only the early appearance of kidney or pelvis activity was indicative of lymphourinary fistula (20). We did not find any early urinary leakage in our last patient imaged, even after using SPECT/CT to improve visualization of the thoracic duct (21).

Chylopericardium is very rare, occurring either secondary to congenital malformations or as consequence of trauma, surgery, Gorham disease, or tumors (22). Chylopericardium could not be clearly demonstrated in patient 15 .

One of the largest studies (18 patients) using lymphoscintigraphy in chylothorax, chyloperitoneum, and chyluria was published in 1998 (23). The authors used ${ }^{99 m}$ Tc-dextran or ${ }^{99 \mathrm{~m}} \mathrm{Tc}$-antimony, there were no children in their cohort, and lymphoscintigraphy was conclusive in $72 \%$ of their patients. Because the study originated from Asia, 11 of the 18 patients presented with chyluria secondary to filariasis. The findings for those 11 were normal in 5, obstruction in 5, and lymphorenal fistula in 1 . The remaining 7 of the 18 patients presented with a combination of chylothorax, chyluria, and chyloperitoneum of various but nonmalignant etiologies. The findings for those 7 were enhanced lymph flow in 1, lymph reflux in 1 , and obstruction in 5 .
In a European study of 16 adult patients (14), the diagnosis was obtained by lymphoscintigraphy in 4 , CT scan in 6 , and a combination of both modalities in 6 . Five patients had chyluria, 8 had chylothorax, and 4 had chyloperitoneum. Only 2 of 5 cases of chyluria were secondary to filariasis. Nine patients had chyle leakage after surgery for neoplasia, and 2 had chyle leakage secondary to tuberculosis. Trauma, not filariasis, was therefore the most frequent origin.

The only large pediatric study using lymphoscintigraphy included 5 neonates and 10 patients between 1.5 and 8 y old (24). The population was different from ours, as most of the children had lymphatic dysplasia, including congenital aplasia and hypoplasia, with lymphedema. Chylous effusion was present but not the main clinical pattern in most.

SPECT/CT has been shown to improve localization $(21,25,26)$, and we have started to use SPECT/CT in some of our more recent patients, with proper immobilization precluding the use of sedation. More recent equipment may improve detection of even a small leak (27). An alternative would be to fuse the SPECT images with contemporary diagnostic CT or MR images.

\section{CONCLUSION}

Lymphoscintigraphy can be performed on children in a variety of settings, such as chylothorax, chylopericardium, chyloperitoneum, chyluria, lymphangiectasia, and lymphangiomatosis. Although technically challenging in babies because of their small size, the test is minimally invasive, is associated with only a low level of radiation exposure, and has no side effectsas opposed to the major morbidity that infants and children otherwise face. To improve diagnostic accuracy, we recommend placing the patient on a high-fat diet, withholding octreotide, injecting the 4 extremities, and imaging with SPECT/CT.

\section{DISCLOSURE}

No potential conflict of interest relevant to this article was reported.

\section{REFERENCES}

1. Szuba A, Shin WS, Strauss HW, Rockson S. The third circulation: radionuclide lymphoscintigraphy in the evaluation of lymphedema. J Nucl Med. 2003;44: 43-57.

2. Kato T, Takase K, Ichikawa H, Satomi S, Takahashi S. Thoracic duct visualization: combined use of multidetector-row computed tomography and magnetic resonance imaging. J Comput Assist Tomogr. 2011;35:260-265.

3. Bessone LN, Ferguson TB, Burford TH. Chylothorax. Ann Thorac Surg. 1971;12: $527-550$.

4. McGrath EE, Blades Z, Anderson PB. Chylothorax: aetiology, diagnosis and therapeutic options. Respir Med. 2010;104:1-8.

5. Valentine VG, Raffin TA. The management of chylothorax. Chest. 1992;102:586-591.

6. Zuluaga MT. Chylothorax after surgery for congenital heart. Curr Opin Pediatr. 2012;24:291-294.

7. Hillerdal G. Chylothorax and pseudochylothorax. Eur Respir J. 1997;10:11571162 .

8. Macnab DS, Scarlett EP. Traumatic chylothorax due to intrathoracic rupture of the thoracic duct. Can Med Assoc J. 1932;27:29-36.

9. Fairfax AJ, McNabb WR, Spiro SG. Chylothorax: a review of 18 cases. Thorax. 1986;41:880-885. 
10. Chan EH, Russell JL, Williams WG, Van Arsdell GS, Coles JG, McCrindle BW. Postoperative chylothorax after surgery in children. Ann Thorac Surg. 2005;80:1864-1870.

11. Kuang-Tao Y. Detection of chylothorax and cervical cystic hygroma in hydrops fetalis using lymphoscintigraphy. Clin Nucl Med. 2006;31:205-206.

12. Moadel-Sernick RM, Crooke GA, Freeman L. Lymphoscintigraphy demonstrating thoracic duct injury in an infant with hypoplastic left heart syndrome. Clin Nucl Med. 2000;25:335-336.

13. Fukahori S, Tsuru T, Asagiri K, et al. Thoracic lymphangiomatosis with massive chylothorax after a tumor biopsy and with disseminated intravenous coagulation: lymphoscintigraphy, an alternative minimally invasive imaging technique: report of a case. Surg Today. 2011;41:978-982.

14. Deso S, Ludwig B, Kabutey NK, Kim D, Guermazi A. Lymphangioscintigraphy in the diagnosis and localization of various chyle leaks. Cardiovasc Intervent Radiol. 2012;35:117-126.

15. Noel AA, Gloviczki P, Bender CE, Whitley D, Stanson AW, Deschamps C. Treatment of symptomatic primary chylous disorders. J Vasc Surg. 2001;34:785-791.

16. Wen Z, Tong G, Liu Y, Meeks JK, Ma D, Yang J. The lymphoscintigraphic manifestation of ${ }^{99 \mathrm{~m}} \mathrm{Tc}$-dextran lymphatic imaging in primary intestinal lymphangiectasia. Nucl Med Commun. 2014;35:493-500.

17. Guglielmo N, Melandro F, Nudo F, et al. Chylous leakage after a laparoscopic live-donor nephrectomy: case report and literature review. Exp Clin Transplant. 2016;14:338-340.

18. Oh JK, Yoon HE, Chung YA. Lymphoscintigraphic demonstration of chyle leak after kidney transplantation and gamma camera detection of radioactivity in chylous aspirate. Clin Nucl Med. 2014;39:760-761.
19. Lv S, Wang Q, Zhao W, et al. A review of the postoperative lymphatic leakage. Oncotarget. 2017;8:69062-69075.

20. Yuan Z, Luo Q, Chen L, Luo Q, Zhu R. The role of lymphoscintigraphy in chyluria. Hell J Nucl Med. 2010;13:238-240.

21. Prevot N, Tiffet O, Avet J Jr, Quak E, Decousus M, Dubois F. Lymphoscintigraphy and SPECT/CT using ${ }^{99 \mathrm{~m}} \mathrm{Tc}$ filtered sulfur colloid in chylothorax. Eur $J$ Nucl Med Mol Imaging. 2011;38:1746.

22. Mandarry MT, Ru XH, Wei ZQ. Primary idiopathic chylopericardium; a rare case with a synopsis of the literature. Singapore Med J. 2012;53:e156-e158.

23. Pui MH, Yueh TC. Lymphoscintigraphy in chyluria, chyloperitoneum and chylothorax. J Nucl Med. 1998;39:1292-1296.

24. Bellini C, Boccardo F, Campisi C, et al. Lymphatic dysplasias in newborns and children: the role of lymphoscintigraphy. J Pediatr. 2008;152:587-589.

25. Weiss M, Schwarz F, Wallmichrath J, et al. Chylothorax and chylous ascites: clinical utility of planar scintigraphy and tomographic imaging with SPECT/CT. Nuklearmedizin. 2015;54:231-240.

26. Das J, Thambudori R, Soumendranath R. Lymphoscintigraphy combined with single-photon emission computed tomography-computed tomography (SPECT-CT): a very effective imaging approach for identification of the site of leak in postoperative chylothorax. Indian J Nucl Med. 2015;30: 177-179.

27. Yang J, Codreanu I, Zhuang H. Minimal lymphatic leakage in an infant with chylothorax detected by lymphoscintigraphy SPECT/CT. Pediatrics. 2014;134: e606-e610. 